\title{
Un ejemplo de relaciones simbióticas en la Guajira del siglo XVIII. \\ Historia de una sublevación bajo el liderazgo del cacique Cecilio
}

\author{
Margarita ReSTREPo Olano \\ Universidad de Medellín \\ mmrestrepo@udem.edu.co
}

Recepción: 23 de julio de 2012 / Revisión: 3 de diciembre de 2012

Aceptación: 12 de diciembre de 2012 / Publicación: diciembre de 2013

\begin{abstract}
Resumen
Este artículo trata sobre el liderazgo del cacique Cecilio y su estrecha relación con los comerciantes de la región guajira, varios de ellos peninsulares dedicados a la práctica del contrabando y unidos también contra la principal autoridad de la región, el teniente de gobernador, José Javier Pestaña, quien a semejanza de otros homólogos quiso hacerse con el control de esta práctica. Esa lucha se tradujo en una sublevación contra el teniente en la que se produjo su muerte y en la que actuaron en connivencia el cacique Cecilio, los comerciantes e incluso algunas autoridades locales. El estallido de 1753 es un ejemplo de "complejidad, flexibilidad y pragmatismo", repitiendo las palabras del historiador noruego Steinar Saether. En definitiva, unas relaciones simbióticas.
\end{abstract}

Palabras clave: cacique, contrabando, sublevación, Guajiros, Río Hacha, siglo XVIII, Nueva Granada, Colombia.

\section{An Example of Symbiotic Relationships in La Guajira during the XVIII Century. The History of a Revolt under Chief Cecilio's Leadership}

\begin{abstract}
This article is about the leadership of Indian Chief Cecilio and his close relationship with the merchants of the Guajira region, some of which were peninsulares dedicated to contraband. These also joined forces against Lieutenant Governor Jose Javier Pestaña, the highest authority in the region, who, like other governors, wanted to gain control of those practices. This struggle stirred in a revolt against the lieutenant, which resulted in his fatality, and in which local merchants and even local authorities were found to be acting in connivance with Chief Cecilio. In the words of the Norwegian historian Steinar Saether, this outbreak of 1753 is an example of "complexity, flexibility and pragmatism". In brief, these were symbiotic relationships.
\end{abstract}

Key words: Chief, Rio Hacha, 18th Century, New Granada, Revolt, Guajiros, Viceroyalty.

Sumario: 1. Presentación. 2. Balance historiográfico. 3. La provincia de Río Hacha, generalidades. 4. El cacique Cecilio: la concentración del poder militar. 5. Evangelización de los Guajiros, "objeto de principal consideración". 6. El teniente Pestaña: por el control del comercio ilícito. 7. "Viva el rey, muera el teniente o salga". Historia de una sublevación. 8. A modo de conclusión. 9. Referencias bibliográficas. 


\section{PRESENTACIÓN}

El control económico y político que la Corona puso en marcha en los territorios hispanoamericanos dio lugar a numerosas tensiones y reacciones, especialmente en la segunda mitad del siglo XVIII.

El interés de la dinastía borbónica por sacar mayor provecho de sus colonias llevó a implementar una serie de medidas fiscales entre las que destacan el establecimiento de nuevos monopolios estatales sobre algunos productos de mayor rendimiento, poner bajo administración directa algunos ramos que antes estaban en arrendamiento $\mathrm{y}$, sobre todo, lograr una mayor eficiencia en el cobro de impuestos que gravaban la minería, la agricultura y el comercio gracias a la creación de nuevas plazas de oficiales reales.

Como respuesta a estas reformas son bastante conocidas, por su trascendencia, las rebeliones de Túpac Amaru (1780), la de los Comuneros del Socorro (1781) ${ }^{1}$ y la de los Barrios en Quito (1765). Sin embargo, en fechas anteriores estallaron numerosas sublevaciones como resultado de algunas medidas que se fueron implementando de manera gradual ${ }^{2}$. Aunque no tuvieron la trascendencia de esas grandes rebeliones, fueron importantes en tanto se puso de manifiesto la resistencia del común de la población al incremento de la presión fiscal efectiva por parte de las autoridades coloniales.

La Guajira fue escenario de varias de esas sublevaciones y, justamente, esa circunstancia ha sido objeto de análisis de algunos historiadores. Entre estos estudios, ha prevalecido la tesis que define las relaciones de los Guajiros con las autoridades coloniales como una confrontación violenta. Sin embargo en el año 2005, el historiador noruego Steinar Saether demostró que era necesario analizarlas con mayor detenimiento pues fueron, por lo menos, "complejas, flexibles y pragmáticas"3. Dicha tesis es justamente la que hemos podido comprobar al estudiar la sublevación que estalló el día 9 de diciembre de 1753 bajo el liderazgo del cacique de los Guajiros, Cecilio López Sierra. De los sucesos que rodearon este episodio y que ponen de manifiesto unas relaciones simbióticas, tratamos en estas páginas.

\footnotetext{
1 Sobre el movimiento de los Comuneros existe una amplia bibliografía. Representativo por su novedosa tesis es el estudio de John L. Phelan, publicado en 1980 y reeditado en 2009. El autor logró demostrar que los Comuneros deseaban preservar el orden existente, las prácticas acostumbradas. Sus fuentes de inspiración no provenían de los filósofos franceses e ingleses, inspiradores de la Revolución norteamericana, sino de los teólogos clásicos españoles de los siglos XVI y XVII, argumenta Phelan. Otros autores han abordado el movimiento como precursor de la Independencia: CÁRDENAS, 1980; RodRíGUEZ 1950. El movimiento también ha sido interpretado como una revolución social: LiÉvano, 2004. Por su parte, un estudio de MCFARLANE publicado en 1999 estableció una conexión entre los distintos incidentes que estallaron durante el siglo XVIII y la rebelión de los Comuneros. A su juicio, muchos de los temas y agravios que se expresaron en el Socorro se pueden encontrar en otros desórdenes ocurridos en la Nueva Granada, incluso muchos de ellos antes de 1781. En la línea de Phelan, McFarlane demostró que las sublevaciones del XVIII, incluido el movimiento de los Comuneros, fueron una defensa de las prácticas tradicionales de la vida comunitaria local.
}

2 Laviana, 1986, pp. 471-507; McFarlane, 1999, pp. 21-72.

3 SAether, 2005, p. 133. 


\section{BALANCE HISTORIOGRÁFICO}

Hasta el momento, la historiografía ha abordado la figura del cacique Cecilio López dentro de estudios generales relacionados con la región guajira durante el periodo colonial. El único estudio particular que conocemos hasta el momento es el de José Polo Acuña, que ha centrado su atención en las acciones del cacique y el conflicto hispano- wayúu en la Guajira entre 1750 y $1770^{4}$.

En los estudios generales sobre la Guajira, la situación ha sido distinta. Las memorias del jesuita Antonio Julián en tiempos borbónicos y las investigaciones contemporáneas de Polo Acuña, Francois René Picón, Fray Antonio de Alcácer, Alberto Tarazona, Antonio García, Petra Josefina Moreno, Eduardo Barrera Monroy, Steinar Saether y Aline Helg, entre otros, han abordado la región desde diferentes ópticas, como veremos en el siguiente balance, en el que la información sobre publicaciones anteriores al año 2000 han sido tomadas del balance ofrecido por Eduardo Barrera Monroy ${ }^{5}$.

Las memorias del jesuita Antonio Julián que llevan por título La perla de América. Provincia de Santa Marta, han sido desde tiempo atrás de obligada lectura. El jesuita recoge en sus páginas el resultado de la visita pastoral que a mediados del siglo XVIII tuvo ocasión de realizar a las misiones de la diócesis samaria en compañía del entonces obispo, José Javier de Arauz 6 .

En tiempos contemporáneos, el capuchino Alcácer publicó en la década de 1950 un estudio sobre las misiones de su orden religiosa ${ }^{7}$. El suyo es un análisis de la labor misionera en el siglo XVIII y la explicación de los conflictos desde la perspectiva de los religiosos. En este trabajo se recoge, entre otros, el diario de campaña del prefecto de las misiones, fray Antonio de Alcoy, quien contó con la compañía del cacique Cecilio. De hecho el viaje misionero partió del pueblo natal del segundo, Boronata. La organización de varios asentamientos indígenas en Manaure y Carrizal figuró como uno de los propósitos del recorrido; justamente el cacique actuó como mediador para el logro de ese objetivo, como lo relata Polo Acuña ${ }^{8}$.

En la década del setenta se conocieron los trabajos de Tarazona y Picón. El primero, llegó a calificar las campañas pacificadoras de los españoles como violentas. Sin embargo a juicio de Barrera Monroy, Tarazona ignora los aspectos culturales de la sociedad indígena privilegiando, en cambio, los aspectos externos del conflicto. Por su parte, la tesis doctoral de François René Picón responde a las razones que llevaron a los indígenas Guajiros a adoptar el pastoreo estableciendo un diálogo entre lo etnográfico y lo histórico. A juicio de Barrera Monroy, la debilidad del trabajo descansa en no otorgarles la suficiente fuerza al comercio y al mestizaje como "explicación de la resistencia y capacidad de adaptación de la sociedad indígena"".

\footnotetext{
4 POLO, 1999.

5 Barrera, 2000, pp. 13- 19.

6 Julián, 1980.

7 AlCÁCER, 1959.

8 Polo, 1999, p. 72.

9 Barrera, 2000, p. 19.
} 
El levantamiento del 2 de mayo de 1769, que consistió en un ataque de los indígenas de Rincón a varios españoles, fue analizado por Antonio García en su trabajo sobre los Comuneros ${ }^{10}$. A su juicio, este episodio, que recoge en uno de los capítulos de la obra, se explica como una reacción ante la represión militar de los españoles, que perseguía acabar con el comercio ilícito. La crítica de Barrera Monroy se centra en la pretensión de García de conectar este levantamiento con el de los Comuneros del Socorro cuando las motivaciones fueron muy distintas. Si bien tuvieron lugar en la segunda mitad del XVIII, es importante establecer sus particularidades. También en la década de 1980, se conoció la tesis doctoral de Petra Josefina Moreno que lleva por título Guajiros - Cocinas. Hombres de Historia 1500 - $1800^{11}$.

José Polo Acuña ha sido autor del mayor número de títulos sobre la región. Primero con un trabajo de carácter general sobre la Río Hacha colonial, para adentrarse luego en estudios más detenidos desde la perspectiva de la "frontera" 12.

Mapa 1. Virreinato de Nueva Granada hacia 1770.

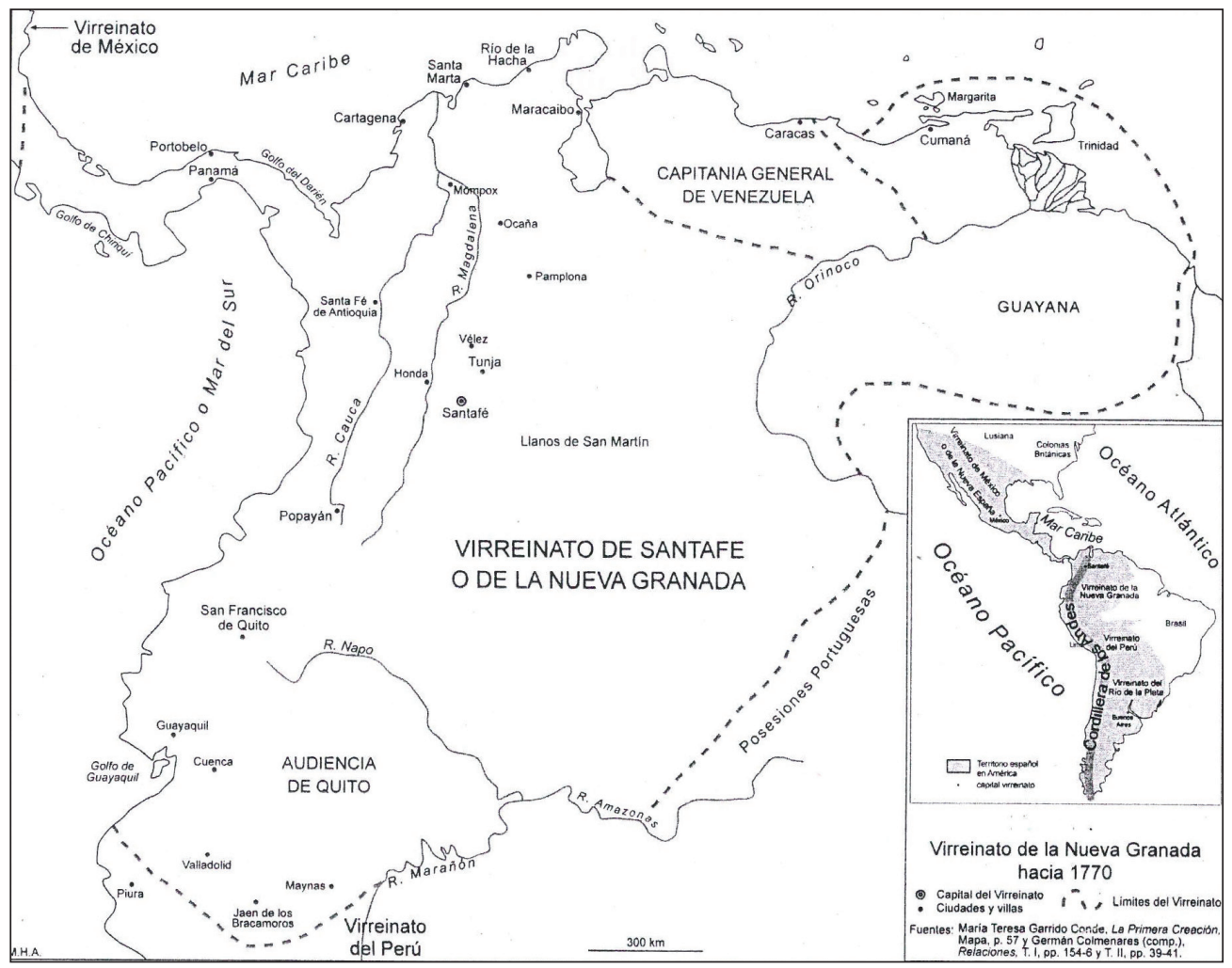

Fuente: Herrera, 2007, p. 126.

10 García, 1981.

11 Moreno, 1984

12 Polo, 1998, pp. 33-49; 2002, pp. 13-31; 2005. 
Su más reciente trabajo se centró en la participación de los Guajiros en la independencia ${ }^{13}$, concretamente, estudia la participación de los grupos indígenas del sur de la Guajira en el proceso de independencia, un asunto que reviste mucha importancia en términos historiográficos porque, como afirma el autor, indios y negros

fueron "silenciados" durante mucho tiempo por una historiografía de corte romántico-liberal, que se ocupó de temas relacionados con las ciudades más importantes (Cartagena, Santa Marta, Río Hacha y Valledupar), descuidando las áreas rurales donde indios y negros eran la población mayoritaria ${ }^{14}$.

En opinión de Eduardo Barrera Monroy, las campañas de pacificación lideradas por la Corona contra los indios Guajiros han contado con varios análisis pero siempre desde la perspectiva española en detrimento de la indígena. De ahí que el autor se haya propuesto recuperar la mirada indígena, la visión de los Guajiros "y los elementos que de esta cultura sirven para explicar los conflictos del siglo XVIII" ${ }^{15}$. Como afirma el propio Barrera, su trabajo está en la línea del publicado por Picón. En todo caso, nos parece excepcional su análisis de las fuentes documentales desde una perspectiva antropológica.

Las relaciones entre guajiros y españoles han sido calificadas comúnmente como una confrontación violenta que terminó en el siglo XVIII con la victoria guajira. Sin embargo, gracias a un análisis mucho más profundo de las fuentes primarias, el historiador Steinar Saether viene a demostrar que no fue así, tesis que coincide con algunas de las actuaciones del personaje objeto de nuestro estudio. Retomando las palabras de Saether, podemos adelantar que las relaciones entre el cacique, como líder de los Guajiros, y las comunidades hispánicas fueron "simbióticas". Se trató de "sociedades distintas y autónomas, [que] hasta cierto grado dependían una de otra y estaban conectadas tanto por la familia como por el comercio"16. La historia del cacique nos permitirá acercarnos a la tesis desarrollada por el historiador noruego.

Durante mucho tiempo la atención de algunos académicos recayó en la población afrodescendiente del Pacífico y del Palenque San Basilio dejando por fuera las provincias caribeñas. Apoyada de un potente acervo documental, Aline Helg ${ }^{17}$ analiza el papel de los afrodescendientes libres y esclavos, la élite blanca y los indígenas entre 1770 y 1835; periodo que, a su juicio, es clave en la construcción de la nación colombiana. La falta de comunicación que se padeció con las provincias de Santa Marta y Cartagena y el escaso control oficial por parte del Estado y de la Iglesia imposibilitó acciones conjuntas dentro de la llamada era de las revoluciones, afirma Helg. Una segunda demostración importante, es cómo

la primacía de formas de resistencia individual, local y transitoria entre los afrocolombianos dieron como resultado esferas particulares de autonomía popular, pero im-

13 Polo, 2011.

14 Ibídem.

15 Barrera, 2000, p. 19.

16 Ibídem, p. 134.

17 Helg, 2011. 
pidieron la formación de una identidad afrocaribeña en la región y un desafío cohesivo a la Colombia andina ${ }^{18}$.

Resulta significativo en la historiografía colombiana el escaso número de investigaciones sobre la Guajira. En 2002 Adelaida Sourdís aportaba un dato revelador: de 322 artículos dedicados al Caribe y que fueron publicados en el Boletín de Historia y Antigüedades, sólo siete centraban su atención en esta región ${ }^{19}$. Aunque se trate de un dato parcial no deja de ser ilustrativo. El balance parece estar cambiando paulatinamente, como venimos confirmando: sólo en los últimos siete años se han publicado los cuatro trabajos que hemos mencionado. El interés reciente por el estudio de la Guajira puede sustentarse, entre otras razones, en las nuevas interpretaciones de los procesos de independencia así como las nuevas miradas que han recibido las élites y las clases populares y, de otro lado, la fuerza de la historia local y regional.

Por último, es importante señalar que, entre los diferentes títulos que se han mencionado, no pocos han abordado la larga historia de conflictos que se explican, en parte, por las particularidades de una zona de frontera y por las difíciles condiciones de evangelización y sometimiento ya entrado el siglo XVIII, entre otras características. Justamente en la línea de los conflictos hemos centrado nuestro interés, en concreto, en la sublevación que tuvo lugar en 1753 en la ciudad de Río Hacha y que contó con el liderazgo del cacique Cecilio. Más allá de relatar los hechos, queremos tomarla como ejemplo de la tesis sostenida por Saether.

\section{LA PROVINCIA DE RÍO HACHA, GENERALIDADES}

Santa Marta y Cartagena, formaban las dos gobernaciones de la costa caribe neogranadina. La de Santa Marta estaba formada por la capital del mismo nombre -que a su vez era sede del obispado- así como por cincuenta ciudades entre las que sobresalían, por su alto número de habitantes, Ocaña, Valle de Upar, Chiriguaná, entre otras. Incluía esta gobernación, la sub-provincia de Río Hacha que, a su vez, reunía las ciudades de Río Hacha, Bahía Honda, Boconcita y otras.

Con amplia fachada sobre el mar Caribe, se levantaba la entidad administrativa de la provincia de Río Hacha cuya máxima autoridad era el teniente de gobernador que, a su vez, era nombrado por el virrey. La situación geográfica privilegiada de la península de la Guajira sobre el Caribe y el conocido comercio de perlas explican el fluido intercambio comercial de la región en época colonial. Río Hacha, al igual que Santa Marta y a diferencia de Cartagena, era una zona con baja densidad de población, un alto índice de indígenas sin evangelizar y una débil presencia de autoridades religiosas y civiles, lo que en parte viene a explicar esa facilidad para la práctica del comercio ilícito, uno de los principales "males" que azotaba a la región Caribe y causa fundamental del restablecimiento del virreinato neogranadino en 1739.

\footnotetext{
18 Ibídem.

19 Sourdis, 2002, pp. 541-552.
} 
Mapa 2. Llanuras del Caribe. Asentamientos nucleados, 1758-1764.

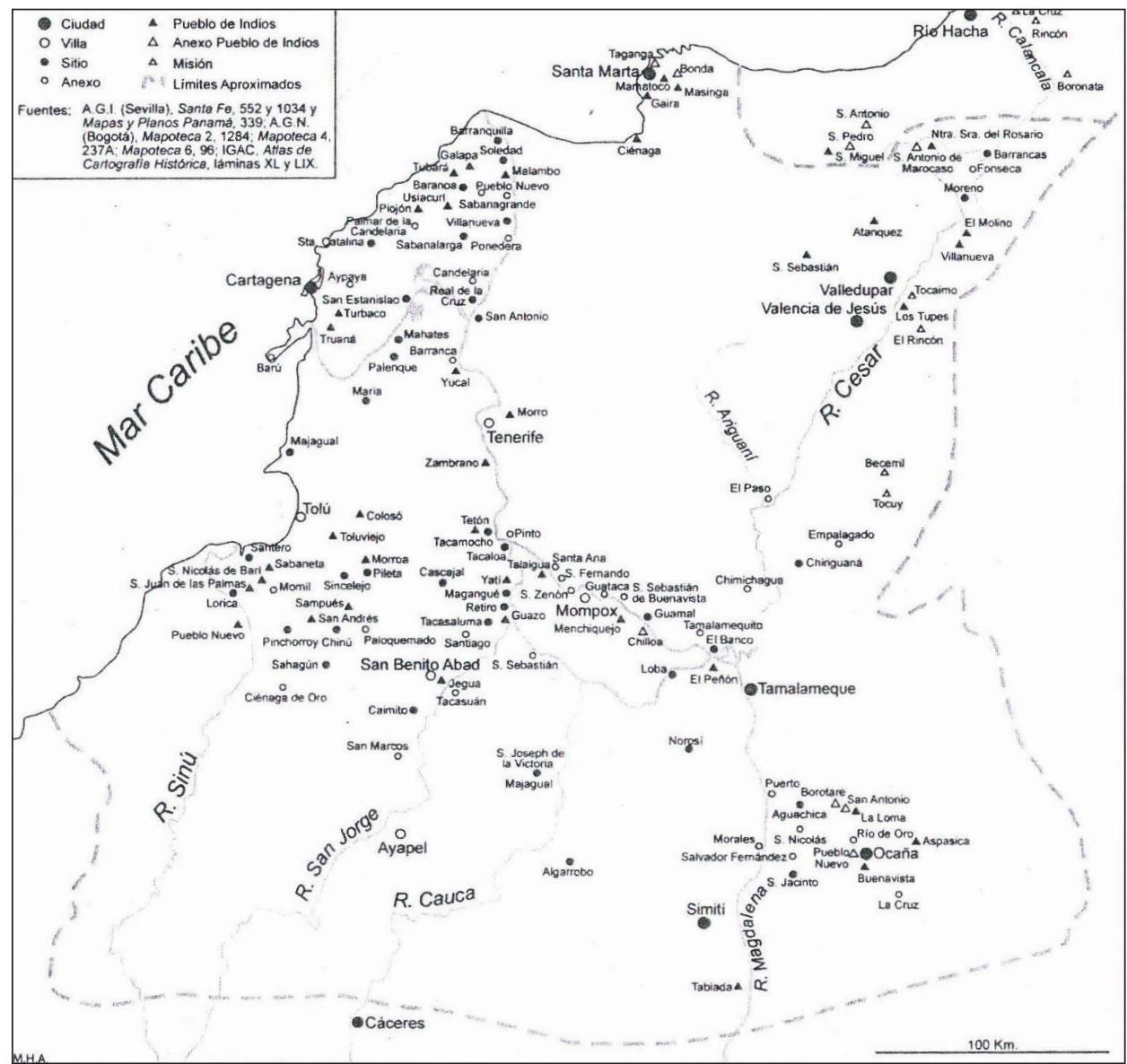

Fuente: Herrera, 2007, p. 292.

Río Hacha se separó de Santa Marta por Real Cédula de 1 de julio de 1790 convirtiéndose en gobernación independiente. Sin embargo, en las Instrucciones de 1743 esta separación ya se daba por hecha, según se lee:

Para el mismo fin he resuelto se separe la provincia del Río del Hacha de la de Santa Marta a la que estaba agregada y donde el gobernador de esta ponía en aquella un teniente... y así ejecutada esta separación pondréis en la provincia del Río del Hacha persona de todas buenas circunstancias que la gobierne ${ }^{20}$.

20 Instrucciones a Juan Francisco Güemes de Horcasitas. Buen Retiro, 12-XII-1743. Archivo General de Indias (en adelante AGI), Santa Fe, 277, art. 80. 
La información sobre la situación administrativa en la década central del siglo es bastante confusa. Según la historiadora Aline Helg desde 1777 hasta 1789 la provincia de Río Hacha estuvo unida a la de Santa Marta y era administrada desde la lejana capital de esta última y, añade, después de 1789, Río Hacha regresó a la condición de provincia separada con su propio gobernador ${ }^{21}$. Queda claro que se había presentado ya una ocasión de separación al advertir que regresaba a esa condición. No obstante, por la información documental que hemos tenido ocasión de conocer, sabemos que en tiempos de Solís Río Hacha dependía administrativamente de Santa Marta y la gobernación recaía en un teniente de gobernador que, a su vez, era nombrado por el virrey.

Tanto Aline Helg como Eduardo Barrera coinciden en afirmar que Río Hacha se erigió en gobernación independiente en 1790. Esta separación de Santa Marta no fue un hecho gratuito, se dio justamente al año siguiente de la expedición del informe de Francisco Silvestre quien afirmaba de modo muy ilustrativo que aunque Río Hacha hacía parte de la provincia de Santa Marta había que hacer de ella particular narración

por comprenderse en su distrito de más de cuarenta leguas la célebre nación guajira, que se mantiene sin conquistar y que se calcula compondrá como cuarenta mil almas de todos sexos y de diez a doce mil indios de $\operatorname{armas}^{22}$.

Sumado al informe de Silvestre, las elevadas proporciones que alcanzó el comercio ilegal, y en aras de reducirlo, se convirtieron en otra motivación para la separación administrativa de Santa Marta y Río Hacha. Sin embargo,

las tensiones entre las dos ciudades se exacerbaron aún más por el cambio de condición administrativa de Río Hacha como medida de la Corona para erradicar el contrabando ${ }^{23}$.

Más allá del asunto administrativo, del momento en el cual fue ascendida a gobernación independiente en un periodo determinado, interesa resaltar que esta confusión evidenciaba las dificultades de aquella zona fronteriza y del poco control del Estado colonial, como lo afirmara la historiadora Marta Herrera Ángel ${ }^{24}$. Esta circunstancia cobra mayor trascendencia al saber que se trataba de una zona presa de las dos principales dificultades de la Corona: la hostilidad de los grupos indígenas aún sin someter y la práctica recurrente del contrabando.

Según el censo de 1778, la provincia de Río Hacha contaba con 3.948 habitantes de los cuales 2.513 eran mestizos, lo que venía a representar un elevado 63 por ciento de la población total, mientras que los indígenas alcanzaban un 16 por ciento. Completaban la distribución étnica los blancos con un $8 \%$ y los esclavos que constituían sólo el $1 \%{ }^{25}$.

\footnotetext{
21 Helg, 2011, p. 165.

22 SiLVESTRE, 2004, pp. 80-81.

23 Helg, 2011, p. 165.

24 Herrera, 2007, p. 127.

25 PÉrez, 1951, pp. 392-393.
} 
Mapa 3. Grupos indígenas de la provincia de Santa Marta, c.1725.

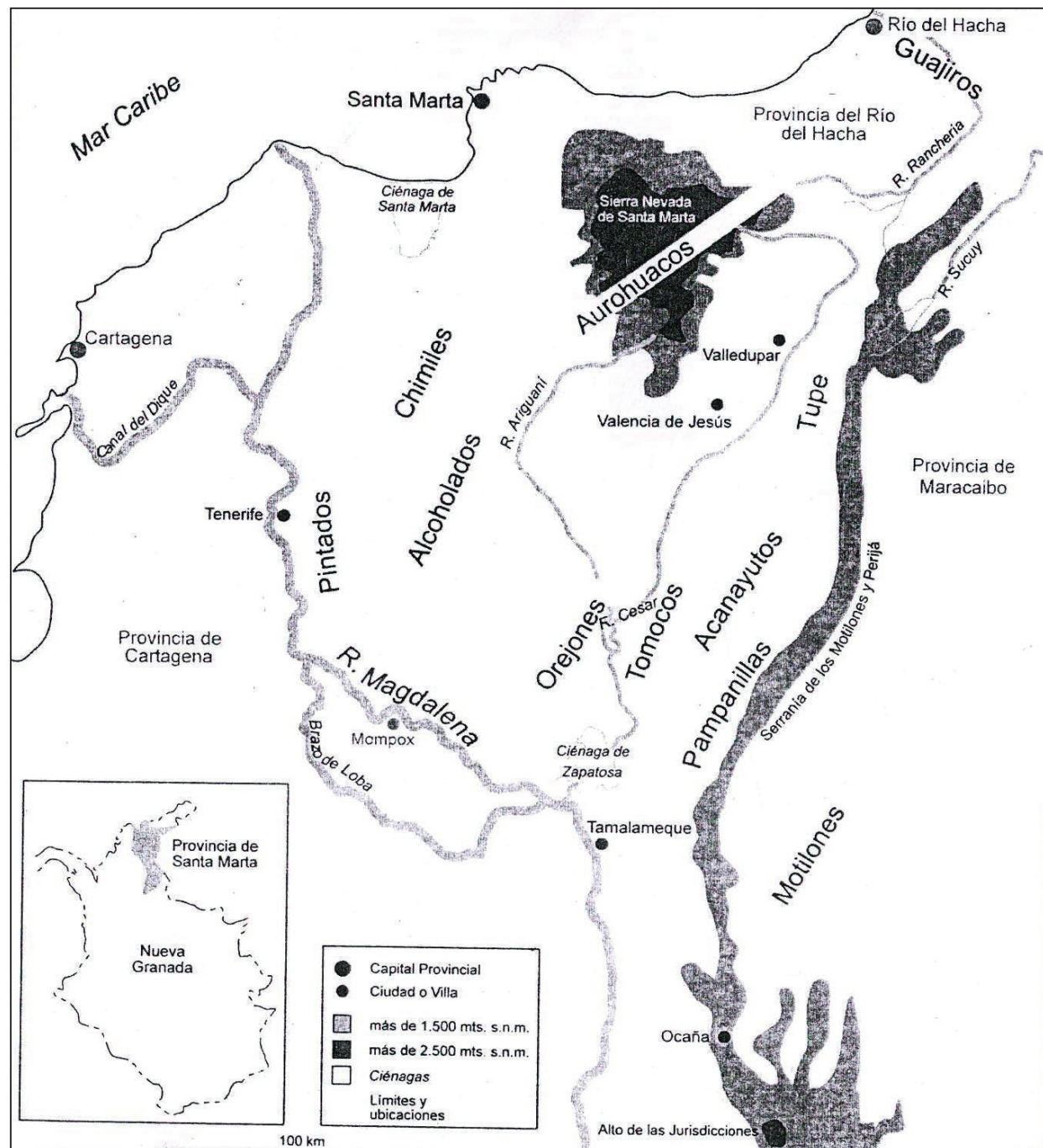

Fuente: HERRERA, 2007, p. 107.

Entre los indígenas que residían en la zona se concentró una de las comunidades que más resistencia opuso al proceso de hispanización: los Guajiros, cuyo cacique por espacio de 50 años, Cecilio López Sierra, es nuestro objeto de estudio. Junto a sus parientes, los Cocinas, los Guajiros llegaron a ser tanto o más peligrosos que los vecinos de Santa Marta, los llamados Chimilas. Si bien el censo de 1778 registra un $16 \%$ de indígenas, esta cifra no alcanza a reflejar el total, toda vez que un amplio sector de la población vivía en los montes, sin sujeción alguna, por fuera de los poblados 
"para mantenerse al margen de la normatividad colonial" ${ }^{26}$. La dificultad de precisar el número total de habitantes la confirmaba en 1778 el gobernador de Santa Marta, Antonio de Narváez, al hacer referencia al cálculo de los naturales:

La de sus primitivos habitantes, los indios, por lo que mira a los no reducidos que constituyen el mayor número es inaveriguable por no estar sujetos a poblaciones regulares y muchos viviendo como fieras en los montes. Los cálculos más verosímiles suponen que los Chimilas, que ocupan la provincia de Santa Marta, sólo serán en el día poco más de 10.000 en todos, y a los Guajiros y demás naciones dependientes que ocupan esta del Hacha los hacen llegar a $30.000^{27}$.

Entre los Guajiros destacaba un importante porcentaje de guerreros. De hecho, de las sublevaciones que estallaron en la costa norte, un elevado número tuvo lugar en Río Hacha bajo liderazgo de estos indígenas ${ }^{28}$. Reveladoras son las siguientes pala-

26 Herrera, 2007, p. 119.

27 Cit. en BARrera, 2000, p. 236.

28 La documentación revisada hasta el momento, así como las investigaciones de Eduardo Barrera Monroy sobre la región Guajira, confirman la profusión de sublevaciones en la costa norte neogranadina especialmente en la segunda mitad del siglo XVIII. Milicias de Valledupar: inspección de ellas, elementos de guerra con que cuenta. Santa Marta, 4-VIII-1777. Archivo General de la Nación (en adelante AGN), Sección Colonia, Fondo Milicias y Marina (en adelante C/MM), T. 76, Doc. 30, ff. 109-115; Escuadra de Cartagena: comunicación sobre lo investigado en la sublevación de las tripulaciones de la escuadra. Cartagena, 11-VI-1764. AGN, C/ MM, T. 55, Doc. 55, ff. 742-745; Sublevación militar en Río Hacha: comunicaciones al respecto. Cartagena, 11-VI-1773. AGN, C/MM, T. 84, Doc. 158, ff. 912-913; Antonio Arévalo, comunicación de Río Hacha sobre investigación de la causa de la sublevación de los indios. Río Hacha, 30-I-1773. AGN, C/MM, T. 124, Doc. 116, ff. 921-922; Sublevación de los guajiros: informe sobre las causas. Santa Fe, 30-IV-1774. AGN, C/MM, T. 132, Doc. 30, ff. 430-431; Jerónimo Mendoza, comandante de Río Hacha: informe sobre la sublevación de los indios goajiros y las disposiciones militares tomadas para debelarla. Río Hacha, 8-VI-1769. T. 138, Doc. 92, ff. 839-872, 965-1004; Narciso Bernales, comandante de Río Hacha, informe sobre sublevación de un indio que estaba en el calabozo. Río Hacha, 2-XII-1784. AGN, C/MM, T. 16, Doc. 48, ff. 244-247; Bernardo Ruiz: correspondencia sobre la expedición para la pacificación y reducción de los goajiros. Río Hacha, 8-IX1761. AGN, C/MM, T. 124, Doc. 30, ff. 177-195; José Galluzo: comunicación sobre pacificación de los indios goajiros y fundación de poblaciones. Río Hacha, 1773. AGN, C/MM, T. 124, Doc. 33, ff. 200-202; José Pestaña y Chuacero: carta-informe de Río Hacha sobre los indios de la Guajira. Río Hacha, 1753. AGN, C/MM, T. 124, Doc. 34, ff. 203-204, 218-219; Antonio Narváez y Latorre, Gobernador de Santa Marta: comunicación sobre pacificación de los goajiros. Santa Marta, 1784. AGN, C/MM, T. 124, Doc. 43, ff. 228-231; Bernardo Ruiz de Noriega: comunicaciones sobre la expedición a su cargo para la reducción, pacificación y conquista de los indios goajiros. Río Hacha, III-1761. AGN, C/MM, T. 124, Doc. 46, ff. 244-286; Hostilidades de los goajiros: comunicación al respecto. San Lorenzo, 11-XI-1778. AGN, C/MM, T. 124, Doc. 57, ff. 326-327; Francisco Baraya y Lacampa, comandante de Río Hacha: informa sobre la nueva rebelión de los indios de la Goajira y solicita fuerza y elementos de guerra. Río Hacha, 1770. AGN, C/MM, T. 124, Doc. 60, ff. 333-345; Real Orden sobre destino de los indios que se hicieron prisioneros en la Goajira. Río Hacha, 1-VI-1779. AGN, C/MM, T. 124, Doc. 61, ff. 346-348; Aprueba el Rey el arbitrio propuesto por el Coronel Don Anastacio Cejudo para pacificar los indios del Rio Hacha por medio de poblaciones y la extracción del palo tinte, Aranjuez, 6-V-1786. AGN, C/MM, T. 124, Doc. 64, ff. 358-362; Gobernador de Río Hacha: comunicación sobre disturbios de los indios de Pedraza, y también, de haber aprehendido al zambo José Antonio Pérez, factor de los disturbios. Río Hacha, 1789. AGN, C/MM, T. 124, Doc. 79, ff. 485-493; Expedición contra los indios de la Goajira: detallado informe sobre ella rendido por José Benito Encio que la comandaba y del gobernador de Río Hacha, sobre estado de la provincia. Río Hacha, 20-I-1761. AGN, C/MM, T. 124, Doc. 81, ff. 496-503; Copia del bando publicado en los pueblos de Boronata, Oriño, La Cruz, El Rincón y Sitio de La Soledad. Informes del gobernador de Cartagena. Boronata, 8-I-1772. AGN, C/MM, T. 124, Doc. 81, ff. 506-525, 629-648; Pacificación y sublevación de los goajiros: comunicaciones y otros documentos pertenecientes. Cartagena, 
bras del historiador Saether que vienen a confirmar la importancia numérica de los Guajiros:

De los grupos no conquistados que seguían existiendo en las provincias de Santa Marta y Río Hacha a finales de la colonia, los Guajiros eran los más numerosos y constituían el mayor problema para las autoridades españolas ${ }^{29}$.

En 1763, por mandato del obispo Gil Martínez Malo, se contabilizaron 8660 hombres de $\operatorname{armas}^{30}$, mientras que en la década de 1780 el virrey Caballero y Góngora hablaba de 10000 guerreros en Río Hacha mientras que por la misma época Silvestre calculaba de "10 a 12000 indios de armas", como lo anotábamos arriba ${ }^{31}$. Si bien no hay cifra exacta, queda claro que los indios de armas no eran una población despreciable, hablar de 9000 o 12000 ya suponía un gran esfuerzo para las autoridades tanto civiles como eclesiásticas.

\section{EL CACIQUE CECILIO: LA CONCENTRACIÓN DEL PODER MILITAR}

Natural de San Nicolás de los Menores y residente en Boronata, Cecilio ostentó el cacicazgo por espacio de 50 años, de 1735 a $1784^{32}$. El cacique general de la nación Guajira, nacido en 1700, era hijo bastardo del capitán peninsular, juez de comisos, alguacil mayor de Santo Oficio y teniente general Jacinto López Sierra, y de la india guajira y cacica de San Nicolás de los Menores, Magdalena Martínez de Gayaso ${ }^{33}$. Al igual que los de Turmequé y de Tibasosa, Cecilio era jefe en una población que como Boronata fue el centro del cacicazgo mestizo más importante para los españoles. No obstante, se trataba de un título tentativo que los españoles le dieron buscando por este medio la sujeción de los indios a un solo jefe, y poder así garantizar el control sobre los aborígenes, cosa que por otro lado jamás lograron dada la organización por clanes de los Guajiros ${ }^{34}$.

Cecilio heredó el cacicazgo de su tío José Lorenzo Salguero en $1735^{35}$ y lo ostentó hasta 1784, cuando aquejado por problemas de salud renunció a favor de su hijo

26-VII-1771. AGN, C/MM, T. 124, Doc. 87, ff. 629-648; José Galluzo: comunicación sobre sublevación de los guajiros, y medidas de inhumana represión que propuso. Cartagena, 11-XI-1775. AGN, C/MM, T. 124, Doc. 92, ff. 680-682; Antonio Arévalo: comunicación de Río Hacha sobre investigación de la causa de la sublevación de los indios. Río Hacha, 1773. AGN, C/MM, T. 124, Doc. 116, ff. 921-922. BarRera Monroy, 2000, pp. 173-220.

29 SAETHER, 2005, p. 132. 234.

30 El censo fue elaborado por el cacique Cecilio López Sierra. Ver resultados en BARRERA, 2000, pp. 233-

31 Silvestre, 2004, pp. 80-81.

32 Confesión del cacique Cecilio. Santa Fe, 20-V-1757. AGN, Colonia, Caciques e Indios, (en adelante C/ CI) T. 48 bis, Doc. 4 , ff. 504 r.-513 v.

33 Certificación de fray Basilio de Alcalá y fray Domingo de Villa. Pueblo de San Joseph, sitio de la Cruz, jurisdicción del rio del Hacha, 10-III 1755. AGN, C/CI, T. 48 bis, Doc. 4, f. 250.

34 BARRERA, 2000, pp. 69-70.

35 Ibídem, p. 70. 
Francisco ${ }^{36}$. A la temprana edad de dos años, por real cédula de 1702 , le fue concedida la gracia de capitán de infantería de los indios Guajiros y de sargento mayor de la misma nación; un hecho que se explica en consonancia con la venta de oficios que alcanzó su culmen entre 1680 y $1740^{37}$. Treinta años después, en 1732, y poco antes de heredar el cacicazgo, el teniente de gobernador de Río Hacha le nombró capitán de la nación Guajira del pueblo de Boronata ${ }^{38}$. Por su parte, el virrey Solís le concedió la merced de maestre de campo, lo que colocaba en sus manos la jefatura militar de la región ${ }^{39}$. Sin duda, una forma de llenar el vacío dejado por la falta de un poder central en la apartada zona de la Guajira y un dato que confirma las particulares relaciones guajiro-hispánicas.

Al poder militar que le conferían sus títulos, se sumaban las posiciones que ejercieron algunos miembros de su familia en Río Hacha, ciudad que mantuvo una estrecha relación con el pueblo de Boronata, residencia del cacique. La documentación hasta el momento revisada revela que algunos miembros de la familia López Sierra alcanzaron posiciones destacadas en la capital de la provincia. Jacinto, padre del cacique, ocupó plazas en el gobierno municipal además de ostentar cargos en la milicia local. De sus hermanos, de parte del padre, tenemos noticia que José fue presbítero mientras que Hermenegildo llegó a ser comandante de milicias de Río Hacha y miembro del cabildo $^{40}$. Por su parte, Diego López Sierra fue regidor y fiel ejecutor mientras que Antonio López Sierra llegó a ser capitán y alcalde ordinario; aunque carecemos de información que lo confirme es probable que se tratara de sus tíos paternos ${ }^{41}$. Lo anterior revela que se trataba de una familia con elevada influencia en las instituciones del poder local, tanto a nivel político como eclesiástico y militar.

El cacique contrajo matrimonio en dos ocasiones. De su primer enlace con María Candelaria Betancur tuvo tres hijos ${ }^{42}$; tras su fallecimiento se casó con Elena Gil de cuya unión nació Cecilio José. Su primera esposa tenía caudal mientras que el cacique, como confesaba él mismo en su testamento, no tenía "cosa alguna". Repitiendo las palabras del cacique, según su testamento:

36 Testimonio del juicio de residencia seguido por don Cosme Damián, juez comisionado, contra don Jacinto López Sierra, alguacil mayor del santo oficio de Río Hacha y contra los alcaldes ordinarios y demás justicias de la misma ciudad. Río Hacha, 1726. AGN, Colonia, Residencias-Magdalena, T. 19, Doc. 3, ff. 434490; Sucesión de Francisco López de Sierra en el cacicazgo de los indios de la Guajira, que tuvo Cecilio López de Sierra, su difunto padre. Santa Fe, 16-IV-1774. AGN, C/CI, T. 64, Doc. 19, ff. 498-517

37 En relación con la venta de oficios en Indias, ver: SANZ, 2009, pp. 243-245.

38 Certificación de Pedro Francisco Bermúdez, juez eclesiástico y de diezmos de la ciudad y provincia de Rio Hacha. Rio Hacha, 8-III-1755. AGN, C/CI, T. 48 bis, Doc. 4, f. 246r.

39 López de Sierra Cecilio, maestre de campo y cacique de la Goajira: se querella contra el comandante Antonio Lascano y Naíza. Boronata, 29-IX-1765. AGN, C/MM, T. 124, Doc. 37, ff. 210-213. En varios documentos con fechas posteriores pudimos confirmar que el cacique hacía mención a su título militar.

40 Certificación de fray Basilio de Alcalá y fray Domingo de Villa. San Joseph, sitio de la Cruz, jurisdicción del Rio del Hacha, 10-III-1755. AGN, C/CI, T. 48 bis, Doc. 4, f. 250v; Hermenegildo Antonio López Sierra, Comandante de Milicias de Río Hacha: comunicación postulando sujetos para oficiales de ellas. Río Hacha, 28-VII-1759. AGN, C/MM, T. 99, Doc. 119, f. 569v.

41 Confirmación del oficio de Diego López Sierra, regidor y fiel ejecutor de Río Hacha. Cartagena, 16XII-1691. AGI, Santa Fe, 162, n 26. José López Sierra, provincial de la Santa Hermandad de Río Hacha. Cartagena, 16-XII-1691. AGI, Santa Fe, 163, nº 1.

42 Testamento del cacique Cecilio López Sierra. Boronata, 27-XII-1764. AGN, C/MM, T. 124, Doc. 107, f. $867 \mathrm{r}$. 
y cuando vinimos al matrimonio tenía la dicha mi mujer caudal; yo cosa alguna, pero confieso y declaro que de dicho caudal no debo cosa ninguna por no haberme hallado aquí al tiempo de su fallecimiento y haberlo disipado sus hijos como también ella en vida ${ }^{43}$.

Sin embargo, la situación mejoraría durante el segundo matrimonio; para ese entonces el cacique tenía "gran caudal". Según su inventario de bienes, disponía de casa, esclavos, ganado cabruno y caballar, una negra con su esposo e hijos, un espadín, un sable, entre otros, así como seis caballos, una mula, una yegua, y 12 reales que se encontraban en manos de unos cuantos deudores ${ }^{44}$.

Entre los méritos de servicio a la Corona que aducía, hablaba de haber contribuido con su propio peculio a la "abertura y facilitación del camino de Maracaibo" y mantenerlo fuera de riesgos para la mejor comunicación entre Río Hacha y Maracaibo $^{45}$.

\section{EVANGELIZACIÓN DE LOS GUAJIROS, "OBJETO DE PRINCIPAL CONSIDERACIÓN"}

A mediados del siglo XVIII después del ataque de Vernon a Cartagena, la reducción de los Guajiros constituía para el ministro Ensenada, "objeto de principal consideración" ${ }^{46}$, sin duda por el peligro que suponía la existencia de una población que podría apoyar un nuevo eventual ataque extranjero a la zona, así como la necesidad de evangelizar a los no pocos Guajiros que andaban sin sujeción alguna por los montes.

La "principal consideración" a la que aludía Ensenada también se asociaba al comercio ilícito que solían practicar los indígenas en connivencia con los comerciantes de la región; la reducción de los indígenas en poblados permitiría frenar, al menos en parte, esas prácticas ilícitas. El contrabando no sólo se explicaba por la posición geográfica del territorio y la débil presencia de autoridades en la zona sino también por las condiciones mismas de la región, toda vez que la península de la Guajira no era propicia para la agricultura por falta de lluvia y escasez de agua.

La evangelización y "conservación" de los indígenas se convirtió en asunto de especial consideración para la Corona, así sea que los motivos últimos fueran de carácter político y estratégico más que religiosos. El elevado porcentaje de la población indígena sin evangelizar en el siglo XVIII se convirtió en uno de los mayores problemas de la provincia de Río Hacha, una situación que pusieron de manifiesto varios de los obispos que ocuparon la mitra samaria e incluso asunto que en un momento quiso solucionar el mismo cacique Cecilio. El que fuera obispo de Santa Marta entre 1714 y 1738, Antonio Monroy, demostró tanta preocupación por la

43 Ibídem.

44 Ibídem.

45 Carta del cacique Cecilio al virrey Messía de la Cerda. Boronata, 29-IX-1765. AGN, C/MM, T. 124. Doc. 37, ff. 210-213.

46 Carta del marqués de la Ensenada al virrey Eslava. Aranjuez, 18-V-1749. AGI, Santa Fe, 575. 
reducción de los nativos que él mismo quiso ir hasta sus tierras a pacificarlos, y llegó hasta ellos repartiéndoles telas, cuchillos y alhajillas; pero, al final, "se rieron del prelado, se retiraron, se huyeron, y lo dejaron burlado" "47. Seis años después, el obispo Nieto Polo pudo constatar el abandono de los Guajiros, pero sus palabras reflejaban una situación ya distinta, porque ellos mismos le pidieron "curas clérigos porque los capuchinos los habían desamparado"48. De aquí que, para este obispo, olvidando quizás lo ocurrido anteriormente, la falta de sujeción de los indios se explicaba por la poca asistencia de los religiosos capuchinos.

A mediados de siglo, las cosas no parecían mejorar, como lo confirmó el obispo José Javier de Arauz en informe redactado tras su visita diocesana. El prelado de origen quiteño encontró varias reducciones desiertas, los indios en los montes y los capuchinos en la ciudad de Valle de Upar, aunque con el ánimo de regresar a los montes a reducir a los gentiles. Lo anterior no dejaba de causarle extrañeza al prelado porque eran muchos los infieles que había en la diócesis y pocos los operarios para atenderlos:

y yo, comentaba Arauz, con imponderable dolor de no poder ocurrir al remedio por no serme facultativo emplearlos en otros ministerios que aquellos para que han sido destinados y de que desean desprenderse y restituirse a Europa ${ }^{49}$.

Fue precisamente esta situación la que llevó a un grupo de comerciantes a diseñar un proyecto que buscaba la conquista de los Guajiros. Los comerciantes eligieron al cacique don Cecilio López Sierra para que expusiera como idea suya ante el rey el proyecto de evangelizar a los Guajiros, suponiendo que así tendría más eco, ya que no era difícil imaginar que el interés de ellos no era sólo, ni principalmente, el evangelizador. Los comerciantes financiaron primero el costoso viaje de don Cecilio hasta Madrid donde se entrevistó, ataviado con su indumentaria, con Fernando VI, y luego, el regreso hasta Santa Fe. En compañía de un comerciante andaluz de "mayores luces" ${ }^{50}$, el cacique se entrevistó en la capital con el virrey. La propuesta consistía en que ellos conquistarían a los Guajiros sin que la Corona tuviera que hacer gasto alguno. A cambio pedían el permiso del asiento de negros esclavos en Santa Marta o en Río Hacha, y establecer en toda la costa el comercio de las harinas que traerían de las colonias extranjeras, uno de los grandes negocios de la región. De aprobarse este proyecto, los comerciantes no solo aumentarían su caudal, sino también se incrementaría la mano de obra indígena y se ampliaría el mercado hispanizado trayendo como resultado una mayor comercialización de los productos y el consiguiente beneficio para la real hacienda.

El virrey Solís no accedió a semejante propuesta. Como buen conocedor de las tramas del comercio y los medios que utilizaban para practicar el contrabando, sabía que "bajo las capas de los negros iban envoltorios" y que los barriles de harinas

\footnotetext{
47 JuLIÁN, 1980, p. 197.

48 Carta del obispo Nieto Polo al rey. Santa Marta, 25-V-1746. AGI, Santa Fe, 523.

49 Carta del obispo Arauz al virrey Pizarro. Ocaña, 15-VI-1751. AGI, Santa Fe, 523.

50 El padre Julián, que los conocía personalmente, no quiso mencionar el nombre del comerciante: "solo el nombre me quedó en la memoria, que honoris causa, omite la pluma”. Julián, 1980, p. 211.
} 
escondían cualquier cantidad de mercancías que entraban en territorio neogranadino por vía ilegítima. El riesgo era muy alto; era abrirle las puertas al contrabando y que algunos religiosos y nativos lo siguieran practicando pasando por alto el buen recaudo de la real hacienda, que llegó a convertirse en una de las principales consideraciones de la Corona, como se refleja en las Instrucciones de gobierno de tres de los virreyes de Nueva Granada entre 1743 y $1760^{51}$. No le compensaba, pues, a la Corona "ahorrarse" el dinero de la empresa evangelizadora.

El misionero jesuita Antonio Julián, secretario del obispo Arauz en la mitra samaria, reveló en sus memorias que el cacique deseaba entregar al monarca toda la nación guajira conquistada ${ }^{52}$. Aunque el deseo de Cecilio López Sierra no fue posible de alcanzar, hizo esfuerzos por mantener el orden de la población. La evangelización y "reducción" de los Guajiros iba más allá de una preocupación de la Corona por convertir a los infieles. Se hacía necesaria para terminar con el trueque que mantenían los indígenas con ingleses y holandeses, "circunstancia que hace más precisa y ejecutiva su reducción porque amenaza mayores daños" ${ }^{53}$.

Tras las acusaciones de la máxima autoridad de la provincia, el cacique se defendía diciéndole "que jamás se había ocupado en introducciones ilícitas" y que su ejercicio había sido "siempre el de gobernar y mantener en paz a los indios Guajiros y contenerlos en sus excesos para que no ofendiesen a los españoles" ${ }^{54}$. Años después, el cacique se quejó ante el virrey Messía de la Cerda porque el comandante le había tratado de manera impersonal y con vilipendio y "de querer dominar sobre todos introduciéndose en el gobierno de los indios que a costa de mi sudor y trabajos tengo agregados a pueblos" ${ }^{55}$. El propio fiscal de la audiencia de Santa Fe llegó a reconocerle al cacique su labor con los Guajiros, confirmando que gracias a su respaldo se habían evitado no pocos inconvenientes ${ }^{56}$.

51 Instrucciones reservadas para José Pizarro. Buen Retiro, 30-III-1749. AGI, Santa Fe, 575. Instrucciones a Juan Francisco Güemes de Horcasitas. Buen Retiro, 12-XII-1743. AGI, Santa Fe, 277. Instrucción reservada a Pedro Messía de la Cerda. Buen Retiro, 1760. AGI, Santa Fe, 575. Cabe señalar que Güemes de Horcasitas siendo Gobernador y Capitán General de Cuba, fue nombrado virrey de Nueva Granada en reemplazo de Sebastián de Eslava quien sería trasladado al Perú; sin embargo el nombramiento no tuvo efecto ya que Eslava no admitió ser trasladado. Ver: El Rey notifica a la ciudad de Santa Fe el virrey que se ha nombrado para aquel reino. Aquí mismo se incluye una nota sobre el Real Decreto de nombramiento de Guemes de Horcasitas pero que finalmente no tuvo efecto por la razón ya señalada. San Ildefonso, 13-XI-1742. AGI, Santa Fe, 541, ff. $130-131$.

52 JuLIÁN, 1980, p. 210.

53 Instrucciones a Juan Francisco Güemes de Horcasitas. Buen Retiro, 12-XII-1743. AGI, Santa Fe, 277, art. 82 .

54 Declaración del cacique Cecilio López Sierra. Santa Fe, 20/21-V-1757. AGN, C/CI, T. 48 bis, Doc. 4. ff. 504 r.-513 v.

55 Carta del cacique Cecilio al virrey Mesía de la Cerda. Boronata, 29-IX-1765. AGN, C/MM, T. 124, Doc. 107, ff. 210-213.

56 Informe del fiscal de la audiencia. Santa Fe, 1-VII-1757. AGN, C/CI, T. 48 bis, Doc. 4, ff.517 r.-518 v. 


\section{EL TENIENTE PESTAÑA: POR EL CONTROL DEL COMERCIO ILÍCITO}

En 1753 tuvo lugar una sublevación en contra de la máxima autoridad de Río Hacha, el teniente de gobernador José Javier de Pestaña. Si bien esta elección descansaba en su dilatada experiencia en la persecución del comercio ilícito -como veremos en el próximo epígrafe-, su actuación pudo ser justamente lo contrario a lo esperado por la Corona. $\mathrm{Y}$ es que no fueron pocos los gobernantes que hicieron caso omiso de esta actividad, especialmente en el XVIII cuando, según Barrera Monroy, se llevó a cabo con mayor intensidad ${ }^{57}$. Según Aline Helg, en 1808 el gobernador José Medina Galindo se había involucrado de tal forma con el contrabando que el virrey Amar y Borbón lo suspendió e inició una investigación exhaustiva de sus actividades ${ }^{58}$.

Eduardo Barrera Monroy recoge de manera más detallada el flagelo del comercio ilícito en la Guajira y gracias a sus investigaciones se confirma la connivencia entre las autoridades y otros sectores de la población. Y es que la Guajira se convirtió en territorio vulnerable a la penetración extranjera carente además de un control efectivo sobre el territorio y sobre sus habitantes. Repitiendo las palabras de Barrera Monroy que ilustran claramente la situación:

A lo largo del análisis del contrabando siempre aparecen involucrados funcionarios en esta actividad. Hasta las naves corsarias españolas que tenían como función controlar el contrabando se dedicaban a fomentarlo ${ }^{59}$.

En la práctica del comercio ilícito participaron muchos sectores de la población que iban desde los españoles pasando por los extranjeros -especialmente franceses, ingleses y holandeses- hasta la población indígena. En este circuito se contaba con la colaboración de las autoridades quienes, según Barrera Monroy, les prestaban colaboración a los comerciantes peninsulares ${ }^{60}$. Dentro de los españoles que ejercían tal actividad figuran los funcionarios de la Corona. Las autoridades coloniales fueron cómplices del trato ilícito seguramente por las difíciles condiciones económicas en que vivían. Es común encontrar para la época continuas quejas de los funcionarios ante sus superiores, por la demora en el pago de los salarios sin dejar de mencionar una causa aún más profunda como los bajos salarios que recibían, lo que nos lleva a pensar que muchos de ellos hicieran oídos sordos a las prácticas del comercio ilícito con tal de obtener dádivas a cambio de su silencio ${ }^{61}$. Como afirma Carmen Borrego Plá, los tenientes de gobernador estuvieron por debajo de los gobernadores en términos salariales, diferencia que sería mucho más pronunciada en el siglo XVIII con la creación de las comandancias generales, entre ellas la de Cartagena.

Tanto Bernardo Ruiz de Noriega, en 1760, como Antonio de Arévalo, en 1774, denunciaron la participación de las autoridades en el comercio ilícito. El primero daba cuenta del monto de las comisiones que debían pagarse a las autoridades para poder

\footnotetext{
57 Barrera, 2000, p. 144.

58 Helg, 2011, p. 164.

59 BARRERA, 2000, p. 147.

60 Ibídem.

61 Borrego, 1983, pp. 274-275.
} 
realizar el comercio ilícito. Por su parte, investigaciones sobre los levantamientos de los Guajiros vincularon a algunos militares en estas prácticas, como lo denunciaba en 1774 Antonio de Arévalo ${ }^{62}$.

La extendida participación de los funcionarios en esta práctica ilícita, como lo revelan Helg y Barrera, y ciertas particularidades de la región, que anotamos a continuación, nos llevan a pensar que el teniente Pestaña antes que responder a los objetivos de la Corona en la persecución del comercio ilícito lo que pretendía era hacerse con el control del mismo. Entre las particularidades de la Guajira señalamos las condiciones geográficas, la dilatada distancia del centro del poder del virreinato, los no pocos indígenas sin evangelizar, la situación económica de los tenientes de gobernador dados sus bajos salarios, la inexistencia prácticamente de otra actividad económica distinta al contrabando en Río Hacha, como afirmara Aline Helg, y la casi generalizada connivencia de los gobernantes. En efecto, la actitud represiva del teniente Pestaña frente a esta práctica ilícita y la posterior sublevación en su contra pueden explicar un cierto deseo de su parte por hacerse con el dominio de esta actividad sustituyendo a los que ya lo dominaban desde hacía mucho tiempo.

Y es que la práctica del contrabando en la Guajira llegó a ser tan extendida que comprometió a los mismos eclesiásticos, según lo llegaron a denunciar las respectivas autoridades.

En respuesta a esas relaciones simbióticas, a las que alude Saether, el cacique Cecilio lideró la sublevación que aquí nos ocupa, y que puede resumirse en el enfrentamiento entre los distintos actores sociales que dominaban el comercio ilícito y un personaje como el teniente Pestaña, deseoso de hacerse con aquel control.

\section{7. "VIVA EL REY, MUERA EL TENIENTE O SALGA". HISTORIA DE UNA SUBLEVACIÓN}

En el mes de diciembre de 1753 tuvo lugar una revuelta liderada por un amplio y heterogéneo grupo de habitantes de la provincia de Río Hacha en contra de su teniente de gobernador, José Javier de Pestaña.

El teniente Pestaña contaba con amplia experiencia en América y treinta años al servicio de la Corona que lo convirtieron en un militar de altas cualidades además de dotarlo de condiciones propias para el ejercicio de cargos en territorios susceptibles de prácticas como el contrabando ${ }^{63}$. Antes de tomar posesión como teniente de gobernador de Río Hacha, Pestaña había ejercido como capitán-comandante de los bajeles corsarios establecidos en Cartagena con el fin de celar el comercio ilícito, comandante de las milicias con el grado de capitán en Santa Marta, teniente de gobernador y capitán a guerra de la provincia de Citará (Chocó) con el empleo anejo de administrador de las cajas reales del distrito, gobernador y juez administrador del juzgado de bienes de difuntos de la provincia del Darién. Su nombramiento confirma el afán de la Corona por asegurar la erradicación de uno de los mayores problemas

62 BARRERA, 2000, p. 148.

63 Carta del virrey Pizarro a Ensenada. Santa Fe, V-1753. AGI, Santa Fe, 1200. 
del virreinato neogranadino. Sin embargo, tanto la actuación del teniente como la posterior rebelión ponen de manifiesto el deseo de Pestaña de hacerse con el control del comercio ilícito sustituyendo a los que ya lo controlaban desde hacía mucho tiempo, como veremos en las siguientes páginas.

La noche del 9 de diciembre de 1753 estalló en la ciudad de Río Hacha una sublevación contra su teniente de gobernador, José Javier de Pestaña, de la que resultó su muerte. Un grupo de aproximadamente 300 personas, en su mayoría españoles y mestizos, liderados por el cacique de los indios Guajiros, se concentraron enfrente de la residencia del teniente con el fin de expulsarlo de la ciudad. La muchedumbre amotinada, entre la que se encontraba el alcalde de la ciudad, conforme iba disparando a su residencia gritaba: "Viva el rey, muera el teniente o salga" manifestándose así el odio a la autoridad local, pero a la vez la confirmación de la lealtad al monarca. Junto a estas arengas, otras de tono más elevado lo calificaron de "tirano y perro", según declaraciones de uno de los testigos ${ }^{64}$. Después de las súplicas de su esposa para que no lo mataran y de que el cacique Cecilio le convenciera, con frases como: "Por la virgen y por el rey que a donde él muera, moriré yo" ${ }^{65}$, el teniente Pestaña se entregó.

En tropel lo sacaron de su casa en dirección al río, donde lo embarcaron en una lancha y hacia las cuatro de la madrugada "lo echaron río abajo a la mar con una escolta por tierra de 25 hombres", para impedir su desembarco. Pero aquello que los rebeldes habían planeado como un exilio forzoso terminó en tragedia, cuando el teniente y dos soldados que le acompañaban murieron ahogados al intentar esquivar una embarcación que, según sospechas de Pestaña, podía ser de origen holandés, tal y como lo relató uno de los sobrevivientes ${ }^{66}$. Y es que entre los perjudicados por la represión del teniente se encontraban los holandeses quienes, a cambio de armas, municiones y hasta negros esclavos, obtenían de los indios Guajiros palo brasil y perlas ${ }^{67}$. Un día antes del motín, el holandés Esteban Ramins escribió una carta en la que solicitaba mercaderes de la región asegurándoles "no tendrían quebranto en sus caudales ni personas". Tanto la vehemencia del mensaje como la "coincidencia" de fechas -la comunicación está fechada un día antes del ataque al teniente-, nos llevan a pensar que los holandeses pudieron tener parte importante en la organización del motín. Como los mercaderes fueron uno de los sectores más golpeados con las medidas de Pestaña, puede pensarse que el holandés Ramins los citó a través de ese comunicado para organizar el motín. El fácil acceso que presentaba la región guajira para las colonias holandesas en las pequeñas Antillas justificaba los intereses en el comercio de contrabando, como señala Saether ${ }^{68}$. El teniente Pestaña, entonces, representaba un obstáculo a las prácticas ilícitas además del temor que despertaba entre los indígenas debido a los malos tratos que les alcanzó a infringir durante su mandato.

\footnotetext{
64 Declaración del testigo Jacinto César. Cartagena, 9-I-1754. AGI, Santa Fe, 1200.

65 Declaraciones del cacique de los Guajiros Cecilio López Sierra. Santa Fe, 1-VII-1757. AGN, C/CI, T. 48 bis. Doc. 4 , s/f.

66 Declaración de Francisco Javier Borreo. Cartagena, 21-I-1754. AGI, Santa Fe, 1200.

67 Carta del obispo de Santa Marta José Javier de Arauz al virrey Pizarro. Ocaña, 15-VI-1751. AGI, Santa $\mathrm{Fe}, 523$.

68 SAether, 2005, p. 133.
} 
A propósito, viene bien mencionar otro caso de sublevación que guarda alguna similitud con la que aquí nos ocupa. En la ciudad de Pasto, en 1781, también resultó asesinado el teniente de gobernador de la provincia en medio de una sublevación indígena. Los amotinados pedían la expulsión de Joseph Ignacio Peredo así como la eliminación del establecimiento del monopolio del aguardiente en la región ${ }^{69}$. Curiosamente ambos territorios, Pasto y Río Hacha, fueron en el periodo independentista reductos realistas lo que, en parte, se explica por su fuerte sentido de autonomía, entre otras razones.

Si bien la sublevación de Río Hacha es un tema que se presta para un profundo análisis, tema incluso de otra investigación, nosotros lo abordaremos desde los episodios que resaltan la figura del cacique y que nos permiten confirmar la existencia de unas relaciones simbióticas entre Guajiros y comunidad hispánica, tal y como lo argumenta Saether. Según la pesquisa del teniente coronel Manuel Martínez de Escobar, se concluyó que el cacique de los Guajiros, Cecilio López Sierra "fue el principal motor que provocó el tumulto y sublevación" ${ }^{70}$. La elección de Martínez de Escobar no era gratuita. Gracias a su anterior experiencia como gobernador del Chocó, había convivido con ciertas circunstancias que se repetían en Río Hacha. Ambos eran territorios de frontera, susceptibles al contrabando al disponer de salida al mar, alejados de la capital y con circunstancias propias de áreas periféricas como un alto porcentaje de indígenas sin evangelizar. En este sentido la elección de Martínez estaba justificada.

La importancia de los indígenas no puede medirse en términos cuantitativos si tenemos en cuenta que tan solo representaron el diez por ciento del total de amotinados, pero sí en su liderazgo y en las distintas motivaciones que les llevaron a unirse al resto de personas. Y es que la presencia de un cacique dotaba al movimiento de cohesión porque "sus acciones muestran que tenían una gran capacidad para generar zozobra entre otros pobladores y entre las autoridades"71.

El cacique confesaba en su declaración haber tenido buenas relaciones con el teniente Pestaña a pesar de haberle culpado en una ocasión de practicar el contrabando con los indígenas en lugar de pacificarlos y "de sugerirlos a alguna revolución"72. De hecho, cuando le convocaron por primera vez a participar en la sublevación junto con sus indios, se negó aduciendo el sentimiento que con dicho teniente tenía. No obstante, después de que un eclesiástico le persuadiera, el cacique accedió a expulsar al teniente e incluso se trasladó desde su pueblo en compañía de 14 indios y 11 zambos para sumarlos al motín. El hecho de que se trasladara desde su lugar de residencia hasta Río Hacha, lugar de la sublevación, pone de manifiesto las relaciones que sostenía con los habitantes de la capital de la provincia, como también lo es que autoridades civiles y eclesiásticas hubieran cursado invitación al cacique, como se desprende de su propio testimonio al preguntársele por los principales motores que suscitaron la sublevación:

69 EARle, 1999, pp. 73-110.

70 Declaración de Solís según pesquisa de Martínez. Santa Fe, 17-II-1756. AGI, Santa Fe, 1200.

71 Herrera, 2007, p. 169.

72 Declaración del cacique Cecilio López Sierra. Santa Fe, 20-V-1757. AGN, C/CI, T. 48 bis, Doc. 4. ff. 504 r. -513 v. 
Agustín y José Salvador Valverde, los dos eclesiásticos y el cabildo. Y que los dos primeros fueron los que impulsaron a los otros y que los eclesiásticos y Juan de Salas fueron los que convidaron al cacique y le dijeron para más obligarle que el cabildo era el que promovía la expulsión del teniente ${ }^{73}$.

Lo anterior viene a confirmar nuevamente el vínculo entre Boronata y Río Hacha; poblaciones que tejieron relaciones comerciales a través del comercio de perlas y frutos. Más significativo aún es cómo se refleja ampliamente la práctica del comercio ilícito por parte de las autoridades civiles y eclesiásticas. Se tiene noticia de que los indígenas se abastecían de víveres en la ciudad, lo que viene a demostrar las dificultades de abastecimiento en los pueblos de indios así como una ausencia de la función del reparto de mercancías, propia de los corregidores ${ }^{74}$. Así mismo, se ponen de manifiesto las estrechas relaciones del cacique con el cabildo. En efecto, eran evidentes toda vez que su hermano Hermenegildo ostentaba una plaza de regidor en el momento de estallar la sublevación, aparte de otros familiares que también formaron parte de la corporación municipal empezando por su padre.

Tras el estallido de la sublevación, el cacique Cecilio fue trasladado a Santa Fe para rendir declaración, permaneciendo en la prisión por algunos días. Fueron también apresados los dos alcaldes de Río Hacha, Luis de Acosta y Fernando Carvajal, el hermano del cacique y miembro del cabildo, Hermenegildo López Sierra, el español Juan Benito de Salas y el comerciante Alberto Luis de Acosta ${ }^{75}$, pues cada uno representaba a los sectores protagonistas ${ }^{76}$.

El fiscal de la Audiencia reconociendo el liderazgo que el cacique Cecilio había alcanzado entre la población y los beneficios que eso le reportaba a la Corona, sugirió condonarle la pena, a pesar de reconocer su participación directa en el motín:

y que se restituya a la residencia de Boronata [al cacique Cecilio] con los mismos y aún mayores honores que antes de este suceso gozaba de que al delincuente de pena capital... se le puede condonar la pena con cuanta mayor razón a este cacique que tiene tan subido concepto entre los Guajiros que pudieran sin el respaldo y sujeción de él traer tamaños inconvenientes a aquella provincia y que aunque por los motivos que van referidos concurrió en alguna parte del tumulto y alboroto de la expulsión ${ }^{77}$.

De los demás culpables entre los que se encontraban el contador Valverde, miembros del cabildo, un peninsular y un comerciante no tenemos noticias de que fueran relevados de su castigo, a saber, la prisión.

La decisión del fiscal no era un hecho aislado, sino que respondía a la recomendación que meses atrás le había elevado el monarca al virrey Solís, probablemente

\footnotetext{
73 Ibídem.

74 Las distintas investigaciones apuntan a que el reparto de mercancías no se puso en práctica en ninguna de las provincias neogranadinas, salvo en el Chocó, y que, en caso de haber existido, no tuvo mayor peso. Ver: Ots Capdequí, 1950, p. 358; Garrido, 1993, p. 236; Herrera, 1992, pp. 20-21; Herrera, 1996, pp. $140-141$.

75 Del otro preso, Luis José Coronel, desconocemos sus ocupaciones.

76 Petición del reo Acosta al virrey Solís. Santa Fe, V-1757. AGN, Criminales, 79.

77 Informe del fiscal de la audiencia José Antonio Peñalber. Santa Fe, 1-VII-1757. AGN, C/CI, T. 48 bis, Doc. 4 , f. 517 v.
} 
motivado por el encuentro que había tenido con el cacique en Madrid unos años antes, como lo comentamos en páginas anteriores. Le adelantaba que debía proceder,

con reflexión de si puede convenir más usar de agasajo con este cacique que de rigor, para granjear por su medio a aquellos indios y que aun cuando considere necesario VA su castigo se le releve de pena capital por haber venido a implorar su real clemencia, dando VA puntual noticia de las resultas de este asunto ${ }^{78}$.

Como había sucedido en tantas otras ocasiones, la Corona optó por la solución menos dramática una vez restaurada la autoridad, con el fin de evitar males mayores, especialmente con una población indígena como la Guajira que tantos problemas había causado desde los primeros momentos de la colonización del territorio. En efecto, la Corona quería también prevenir los perjuicios que la ejecución del cacique causaría a la ciudad pues, según lo anunció Collado, "siendo cabeza de una muchedumbre de indios guerreros podrá con sus hostilidades ponerla en estado de abandonarla por la flaqueza de sus habitantes" 79 . Lo anterior cobra mayor importancia al conocerse que a mediados del XVIII el número de Guajiros sin evangelizar era muy elevado. En situaciones como esta, la Corona era consciente de que esa población "vaga y volante", que vivía fuera del control político del Estado, podía atentar contra el orden establecido.

\section{A MODO DE CONCLUSIÓN}

Entre las palabras que mejor reflejan la influencia de los caciques sobre las poblaciones indígenas que les estaban en cierto modo encomendadas, viene muy bien recordar aquellas pronunciadas por el cronista Polo de Ondegardo: "puede más un curaca y cacique de estos para introducir la fe y conservar en la vida cristiana, que cien frailes juntos" $"$. Si bien esta afirmación es ilustrativa de los Andes, puede hacerse extensiva al levantamiento liderado por el cacique de los Guajiros, Cecilio López Sierra, un liderazgo que dotó a la revuelta de cohesión. Aunque el número de indígenas de la región Caribe no puede compararse con el elevado número de los Andes, es preciso resaltar la gran capacidad para provocar zozobra.

Como comentábamos en la presentación, la sublevación del cacique se ajusta a la tesis defendida por el historiador Saether: las relaciones guajiro-hispánicas fueron "muchísimo más complejas, flexibles y pragmáticas". Una tesis que difiere de la defendida por otros autores quienes han calificado estas relaciones como "una lucha más o menos continua y violenta" ${ }^{81}$. El cacique lideró un movimiento heterogéneo en contra de un funcionario real que quería hacerse con el control del comercio ilícito. La actitud del teniente Pestaña resultaba, a todas luces, incómoda para sectores

\footnotetext{
78 Carta del rey al virrey Solís. Madrid, 17-IX-1756. AGI, Santa Fe, 1200.

79 Carta del gobernador de Maracaibo, Francisco Collado, al ministro Arriaga. Maracaibo, 16-IV-1755. AGI, Santa Fe, 1200.

80 O'Phelan, 1995, p. 37.

81 SAether, 2005, p. 133.
} 
que venían beneficiándose del comercio ilícito en la costa, a saber, los Guajiros, los comerciantes holandeses, mestizos, españoles y hasta los misioneros. Resulta significativo que un personaje como el cacique Cecilio, líder de tales prácticas, llegara a colaborar con la Corona en materias de especial consideración como la evangelización. Es aquí donde se pone de manifiesto el pragmatismo al que alude Saether.

Y es que el liderazgo de Cecilio López Sierra fue utilizado en beneficio de la causa evangelizadora. Su participación en ella permitía la reducción de algunos indígenas que se encontraban aún sin sujeción alguna en pueblos de misión. Esa reducción además permitía un control sobre prácticas ilícitas como el intercambio que realizaban los indígenas con los holandeses e ingleses y, muy seguramente, con otros comerciantes del amplio escenario del Caribe que tantas pérdidas le ocasionaban a la hacienda.

El pragmatismo, la complejidad y la flexibilidad se evidenciaron en la actitud adoptada por las autoridades peninsulares en beneficio del cacique. La Corona era consciente del liderazgo de Cecilio y, por lo tanto, de las desafortunadas consecuencias que podría generar un castigo mayor al que finalmente se le impuso. Por ejemplo, un levantamiento multitudinario de la población guajira en contra de las autoridades peninsulares generaría, sin duda, un mal mayor. Y es que estamos ante un personaje de grandes connotaciones en la región; sin duda un líder como ha quedado reflejado a lo largo del texto. Su influencia se ponía de manifiesto en hechos como la colaboración con la causa evangelizadora y, como consecuencia, el "control" de la práctica del contrabando en las costas, como anotábamos en páginas anteriores. De otro lado, la influencia del cacique también se demostró a través de su patrocinio económico en beneficio de la construcción del camino entre Maracaibo y Río Hacha, como también ha quedado registrado en este artículo, según documentación analizada.

Aunque no tenemos suficientes argumentos que así lo demuestren, podríamos afirmar preliminarmente que la Corona alimentaba esa simbiosis porque era consciente de los prejuicios que podría acarrear el enfrentamiento directo con el cacique. De manera también exploratoria, podemos afirmar que a pesar de que la Corona supiera de las prácticas ilícitas del cacique, le beneficiaba tener con él ciertas gabelas.

Otro asunto de consideración que bien merecería una investigación posterior, es analizar la resistencia de Cecilio desde la postura realista que asumió la Guajira en tiempos independentistas. En páginas anteriores mencionábamos un caso ocurrido en Pasto y aunque esta sublevación guarda diferencias con la de Río Hacha, cabe señalar que ambos territorios serían en el periodo independentista reductos realistas lo que, en parte, se explica por su fuerte sentido de autonomía, entre otras razones que serían tema de posteriores investigaciones ${ }^{82}$. En efecto, la interpretación de Saether viene a sustentar, en parte, la fidelidad a la causa realista en el proceso independentista, al igual que ocurrió en Pasto. En ambas regiones los intereses locales primaron sobre los ideológicos y su fuerte autonomía les permitió construir una dinámica distinta al resto del territorio. Un hecho ilustrativo fue la defensa que hicieron de la causa realista en el proceso independentista que dio inicio a la vida republicana en 1819.

Finalmente, el indulto del cacique permite comprender la postura realista que adoptaron los Guajiros en el proceso independentista que dio inicio a la vida republicana

82 EARLE, 1999, pp. 73-110. 
en 1819. Viene bien hacer referencia al cacique de Mamatoco, población de la provincia de Río Hacha, cuando en el siglo XIX enfrentando a los patriotas republicanos "peleaba por la preservación de un orden monárquico y colonial que había asegurado ciertos privilegios y derechos para los descendientes de los habitantes nativos y de las provincias" ${ }^{83}$. Es probable que si el cacique Cecilio hubiera sobrevivido al periodo independentista habría asumido la misma postura de su coterráneo.

\section{REFERENCIAS BIBLIOGRÁFICAS}

AlCACER, Fray Antonio de O.F.M.,

1959 Las misiones capuchinas en el Nuevo Reino de Granada hoy Colombia. Puente del Común, Chía. Ediciones Seminario Seráfico Misional Capuchino.

BArrera Monroy, Eduardo

2000 Mestizaje, comercio y resistencia. La Guajira en la segunda mitad del siglo XVIII. Bogotá. Instituto Colombiano de Antropología e Historia.

Borrego Plá, María del Carmen

1983 Cartagena de Indias en el siglo XVI. Sevilla. Escuela de Estudios Hispanoamericanos.

BricEÑo, Manuel

1977 Los comuneros. Bogotá. Carlos Valencia Editores.

CÁrdenas Acosta, Pablo

1980 El movimiento comunal de 1781 en el Nuevo Reino de Granada. Bogotá. Tercer Mundo.

EARLE, Rebeca

1999 "Rebelión indígena y reformas borbónicas: sublevaciones en Pasto, 1780-1800". En Mejía Pavony - Larosa - Nieto Olarte (eds.), Colombia en el siglo XIX. Bogotá. Planeta, pp. 73-110.

García, Antonio

1981 "Los levantamientos goajiros y el ordenamiento capitalista del Caribe". En García, (ver.) Los Comuneros 1781-1981. Bogotá. Plaza y Janés, pp. 129-138.

GARRIDO, Margarita

1993 Reclamos y representaciones. Variaciones sobre la política en el Nuevo Reino de Granada, 1770- 1815. Bogotá. Banco de la República.

Helg, Aline

2011 Libertad e igualdad en el Caribe colombiano, 1770-1835. Medellín. Fondo Editorial Universidad Eafit.

Herrera Ángel, Marta

1992 "El corregidor de naturales y el control económico de las comunidades: cambios y permanencias en la provincia de Santa Fe, siglo XVIII". Anuario Colombiano de Historia Social y de la Cultura. Bogotá, n² 20. pp. 7-25.

1996 Poder local, población y ordenamiento territorial en la Nueva Granada, siglo XVIII. Bogotá. Archivo General de la Nación.

2007 Ordenar para controlar. Medellín. La Carreta.

83 SAether, 2005, p. 33. 
Julián, Antonio, S.J.

1980 La perla de América. Provincia de Santa Marta [1787]. Bogotá. Academia Colombiana de Historia.

Laviana, María Luisa

1986 "Movimientos subversivos en la América española durante el siglo XVIII. Clasificación general y bibliografía básica". Revista de Indias. Madrid, vol. XLVI, n 178. pp. 471-507.

LiÉvano AguirRe, Indalecio

2004 Los grandes conflictos sociales y económicos de nuestra historia [1964]. Bogotá. Intermedio.

McFarlane, Anthony

1999 “Desórdenes civiles y protestas populares". En Mejía Pavony - Larosa - Nieto OlarTE (eds.), Colombia en el siglo XIX. Bogotá. Planeta, pp. 21-72.

Moreno, Petra Josefina

1984 Guajiros - Cocinas. Hombres de Historia, 1500 - 1800. Madrid. Tesis Doctoral Inédita. Universidad Complutense.

O' PHELAn, Scarlett

1995 La gran rebelión en los Andes. De Túpac Amarú a Túpac Catari. Cusco. Centro de Estudios Regionales Andinos Bartolomé de las Casas.

Ots CAPdequí, José María

1950 Instituciones de gobierno en el Nuevo Reino de Granada durante el siglo XVIII. Bogotá. Universidad Nacional de Colombia.

Pérez Ayala, José Manuel

1951 Antonio Caballero y Góngora, Virrey y arzobispo de Santa Fé, 1723-1796. Bogotá. Imprenta Municipal.

Phelan, John Ledy

2009 El pueblo y el rey. [1980]. Bogotá. Universidad del Rosario.

Pichón, Francisco

1947 Geografía de la península Guajira. Santa Marta. Escoffet.

Polo Acuña, José

1998 “Aspectos históricos de Río Hacha durante el periodo colonial”. Historia Caribe. Barranquilla, vol. 2, n 3. pp. 33-49.

1999 "Una mediación fallida: las acciones del cacique Cecilio López Sierra y el conflicto hispano-wayúu en la Guajira, 1750-1770”. Historia Regional. Barranquilla, vol. II. nº 4. pp. 67-76.

2002 “Identidad étnica y cultura en una frontera del Caribe: la Guajira 1700-1800”. Aguaita. Revista del Observatorio del Caribe Colombiano. Cartagena, $\mathrm{n}^{\circ}$ 8. pp. 13-31.

2005 Etnicidad, conflicto social y cultura fronteriza en la Guajira, 1700-1850. Bogotá. Universidad de los Andes - Ceso - Observatorio del Caribe colombiano.

2011 "Los indígenas de la Guajira en la independencia de las provincias caribeñas de la Nueva Granada: una aproximación”. Memoria y Sociedad. Bogotá, vol. 15, nº 30.

Restrepo Olano, Margarita

2009 Nueva Granada en tiempos del virrey Solís, 1753-1761. Bogotá. Universidad del Rosario - Universidad de Medellín. 
Rodríguez Plata, Horacio

1950 "Los Comuneros". En Curso Superior de Historia de Colombia. Bogotá. Editorial ABC.

SAETHER, Steinar A.

2005 Identidades e independencia en Santa Marta y Río Hacha, 1750-1850. Bogotá. Instituto Colombiano de Antropología e Historia.

SÁnZ TAPIA, Ángel

2009 ¿Corrupción o necesidad? La venta de cargos de gobierno americanos bajo Carlos II (1674-1700). Madrid. Consejo Superior de Investigaciones Científicas.

SouRDIS, Adelaida

2002 “El Caribe en el Boletín”. Boletín de Historia y Antiguedades. Bogotá, vol. 89, n 818. pp. 541-552.

SiLVESTRE, Francisco

2004 "Apuntes Reservados particulares y generales del estado actual del virreinato de Santafe de Bogotá" [1789]. En Colmenares, (ed.) Relaciones e informes de los gobernantes de la Nueva Granada. Vol. 2. Bogotá. Biblioteca Banco Popular. 